\title{
The EUMETSAT sea ice concentration climate data record
}

\author{
Rasmus T. Tonboe ${ }^{1}$, Steinar Eastwood ${ }^{2}$, Thomas Lavergne ${ }^{2}$, Atle M. Sørensen ${ }^{2}$, Nicholas Rathmann ${ }^{3}$, \\ Gorm Dybkjær $^{1}$, Leif Toudal Pedersen ${ }^{1}$, Jacob L. Høyer ${ }^{1}$, and Stefan Kern ${ }^{4}$ \\ ${ }^{1}$ Danish Meteorological Institute, Lyngbyvej 100, Copenhagen, 2100, Denmark \\ ${ }^{2}$ Norwegian Meteorological Institute, P.O. Box 43, Oslo, 0313, Norway \\ ${ }^{3}$ University of Copenhagen, Juliane Maries Vej 30, Copenhagen, 2100, Denmark \\ ${ }^{4}$ Integrated Climate Data Center (ICDC) University of Hamburg, Grindelberg 5, Hamburg, 20144, Germany
}

Correspondence to: Rasmus T. Tonboe (rtt@dmi.dk)

Received: 4 February 2016 - Published in The Cryosphere Discuss.: 17 March 2016

Revised: 16 August 2016 - Accepted: 24 August 2016 - Published: 28 September 2016

\begin{abstract}
An Arctic and Antarctic sea ice area and extent dataset has been generated by EUMETSAT's Ocean and Sea Ice Satellite Application Facility (OSISAF) using the record of microwave radiometer data from NASA's Nimbus 7 Scanning Multichannel Microwave radiometer (SMMR) and the Defense Meteorological Satellite Program (DMSP) Special Sensor Microwave/Imager (SSM/I) and Special Sensor Microwave Imager and Sounder (SSMIS) satellite sensors. The dataset covers the period from October 1978 to April 2015 and updates and further developments are planned for the next phase of the project. The methodology for computing the sea ice concentration uses (1) numerical weather prediction (NWP) data input to a radiative transfer model for reduction of the impact of weather conditions on the measured brightness temperatures; (2) dynamical algorithm tie points to mitigate trends in residual atmospheric, sea ice, and water emission characteristics and inter-sensor differences/biases; and (3) a hybrid sea ice concentration algorithm using the Bristol algorithm over ice and the Bootstrap algorithm in frequency mode over open water. A new sea ice concentration uncertainty algorithm has been developed to estimate the spatial and temporal variability in sea ice concentration retrieval accuracy. A comparison to US National Ice Center sea ice charts from the Arctic and the Antarctic shows that ice concentrations are higher in the ice charts than estimated from the radiometer data at intermediate sea ice concentrations between open water and $100 \%$ ice. The sea ice concentration climate data record is available for download at www.osi-saf.org, including documentation.
\end{abstract}

\section{Introduction}

The Arctic sea-ice-covered area and extent has decreased since the 1970s (Cavalieri and Parkinson, 2012). In Antarctica there are large regional differences in trends but overall the sea ice extent is increasing because of changing atmospheric circulation patterns and regional cooling (Comiso et al., 2011; Holland and Kwok, 2012). The climatic trends in sea ice extent have been documented using models (Zhang and Walsh, 2006; Goosse and Zunz, 2014), ice charts (Rayner et al., 2003) and in particular the passive microwave data record from US satellite microwave radiometers (Parkinson and Cavalieri, 2008; Cavalieri and Parkinson, 2012). Throughout this paper the sea ice extent is defined as ice-covered waters with ice concentrations derived from microwave radiometer data greater than $30 \%$ and at a grid resolution of $12.5 \mathrm{~km} \times 12.5 \mathrm{~km}$.

The brightness temperatures measured by the satellite radiometers at the atmospheric window channels are dominated by surface emission. However, the measured brightness temperatures are also affected by weather conditions such as wind roughening of the ocean surface, water vapour, and cloud liquid water (Wentz, 1983, 1997; Andersen et al., 2006b). These parameters have trends over the observing period (Wentz et al., 2007). Even though the sensitivity to these parameters is minimized in ice concentration algorithms in general, different algorithms still have different sensitivities (Andersen et al., 2006b). Here we define the noise as the ice concentration fluctuations caused by the instrument electronic components, ice and water surface emissivity variability, and weather conditions, i.e. estimated ice concentra- 
tion variability not caused by changes in the actual ice concentration.

Because of the algorithms' different sensitivities to the noise, and because the noise has climatic trends, the differences also appear as trends in the sea ice extent trends (Andersen et al., 2007). To minimize these artificial trends caused by noise we must (1) find algorithms with low sensitivities to the atmospheric and surface emissivity variability, (2) correct the brightness temperatures for the properties that we are able to quantify (numerical weather prediction (NWP) data: near-surface wind and air temperature and columnar atmospheric water vapour content), (3) calibrate the algorithms to the actual ice and water signatures using dynamical tie points, and finally (4) quantify the residual uncertainties. The EUMETSAT sea ice concentration climate data record (ESICR) is generated according to these principles, (1)-(4), and is based on the NASA's Nimbus 7 Scanning Multichannel Microwave Radiometer (SMMR) (1978-1987), the Defense Meteorological Satellite Program's (DMSP) Special Sensor Microwave/Imager (SSM/I) (1987-2009), and the DMSP's Special Sensor Microwave Imager and Sounder (SSMIS) (2003-today) radiometer data. It uses a combination of the Bristol (Smith, 1996) and the Bootstrap (Comiso, 1986) algorithms with dynamical tie points and explicit atmospheric correction using NWP data for error reduction, and it comes with spatially and temporally varying sea ice concentration uncertainty estimates describing the sea ice concentration accuracy.

Dynamical tie points are typical signatures of sea ice and water required to compute the sea ice concentration from the measured brightness temperatures. These are derived on a daily basis for each hemisphere and therefore adjust the algorithms to the current signatures of ice and water (see Sect. 2.1).

The sea ice concentration uncertainty estimates are needed when the ice concentration data are compared to other datasets or when the ice concentrations are assimilated into numerical models. The mean accuracy of some of the more common algorithms used to compute ice concentration from SSM/I data, such as the NASA Team and Bootstrap, is reported to be 1-6\% in winter (Steffen and Schweiger, 1991; Emery et al., 1994; Belchansky and Douglas, 2002). The overall accuracy of the SMMR total ice concentrations is estimated to be $\pm 7 \%$ (Gloersen et al., 1992). During summer the uncertainties are larger than during winter (Ivanova et al., 2015).

The ESICR data are available at the EUMETSAT's Ocean and Sea Ice Satellite Application Facility (OSISAF) home page (osisaf.met.no), including the validation report (Tonboe et al., 2015b) and the product user manual (Eastwood et al., 2015).

\subsection{Description of the Nimbus 7 SMMR instrument and data}

The SMMR instrument on board the Nimbus 7 satellite operated from October 1978 to August 1987 (Gloersen et al., 1992). The instrument had 10 channels at five frequencies $(6.6,10.7,18.0,21.0,37.0 \mathrm{GHz})$ and vertical (v) and horizontal (h) linear polarization. Each of the channels has different spatial resolution on the ground spanning from $148 \times 95 \mathrm{~km}$ at $6 \mathrm{GHz}$ to $27 \times 18 \mathrm{~km}$ at $37 \mathrm{GHz}$. The across-track scanning was accomplished by tilting the reflector from side to side while maintaining a constant incidence angle on the ground of about $50.2^{\circ}$. The scan track on the ground formed a $780 \mathrm{~km}$ wide arc in front of the satellite (Gloersen and Barath, 1977). Because of the satellite orbit inclination and swath width there is no coverage polewards of $84^{\circ}$. SMMR data were acquired every second day because of satellite power limitations. Data were provided by the National Snow and Ice Data Center (NSIDC) as brightness temperatures in swath projection (Meier, 2008).

\subsection{Description of the SSM/I and SSMIS instruments and data}

The SSM/I instruments onboard the DMSP satellites are conically scanning instruments with seven channels at $19.35 \mathrm{v}$, $19.35 \mathrm{~h}, 22.2 \mathrm{~h}, 37.0 \mathrm{v}, 37.0 \mathrm{~h}, 85.5 \mathrm{v}$, and $85.5 \mathrm{~h}$. The spatial resolution on the ground is $69 \times 43 \mathrm{~km}$ at $19 \mathrm{GHz}$ and $15 \times 13 \mathrm{~km}$ at $85 \mathrm{GHz}$. The incidence angle is $53.1^{\circ}$ and the swath width on the Earth's surface is about $1400 \mathrm{~km}$. There is no coverage polewards of $87^{\circ}$ for the same reason as for SMMR (Sect. 1.1). The different satellites and their operation periods are listed in Table 1. The SSM/I data (version 6 and not the newer version 7) were purchased by EUMETSAT from Remote Sensing Systems (RSS) as antenna temperatures and converted to brightness temperatures using RSS software. The RSS SSM/I version 6 post-processing includes geolocation correction, sensor calibration and quality control procedures, and intercalibration between the different satellites from overlapping periods. These procedures are documented in the RSS SSM/I user manuals (Wentz, 1991, 1993, 2006).

The SSMIS is a continuation of the SSM/I series of instruments onboard the DMSP satellites but with an extension in the number of channels. SSMIS has 24 channels between 19 and $183 \mathrm{GHz}$. The 19 and $37 \mathrm{GHz}$ channels which are used in the ESICR have identical frequencies on SSM/I and SSMIS. However, SSMIS has a swath width of about $1700 \mathrm{~km}$ which gives near-complete daily coverage of the Arctic Ocean. The SSMIS data are from the L2B near-real-time data stream issued via EUMETCast and processed at the US National Ocean and Atmospheric Administration (NOAA). 
Table 1. The satellite missions carrying the SMMR, SSM/I, and SSMIS instrument and the periods they cover.

\begin{tabular}{lll}
\hline Sensor & Launch & End \\
\hline Nimbus 7 SMMR & October 1978 & August 1987 \\
DMSP F8 SSM/I & June 1987 & December 1991 \\
DMSP F10 SSM/I & December 1990 & November 1997 \\
DMSP F11 SSM/I & November 1991 & May 2000 \\
DMSP F13 SSM/I & March 1995 & November 2009 \\
DMSP F14 SSM/I & May 1997 & August 2008 \\
DMSP F15 SSM/I & December 1999 & - \\
DMSP F16 SSMIS & October 2003 & - \\
DMSP F17 SSMIS & November 2006 & - \\
\hline
\end{tabular}

\subsection{Meteorological data}

The NWP model meteorological data are used for reduction of the brightness temperatures for atmospheric noise with a radiative transfer model. European Centre for Medium-range Weather Forecast (ECMWF) ERA-40 data are used for the period from 1978 to 2002, and ECMWF data from the operational models are used from 2002 onwards. A description of the ERA-40 meteorological data archive and the reanalysis can be found in Kållberg et al. (2004).

\subsection{Moderate Resolution Imaging Spectroradiometer (MODIS) data}

The coarse resolution of the passive microwave brightness temperature measurements gives rise to an additional uncertainty when sea ice concentration is computed at finer grid spacing. We call this the smearing uncertainty and it is estimated using a smearing model (see Sect. 2.4.2). High-resolution ice concentration data are used as input to the smearing model: cloud-free and non-calibrated MODIS scenes from the NASA image gallery archive (http:// rapidfire.sci.gsfc.nasa.gov/cgi-bin/imagery/gallery.cgi) were selected manually for their different sea ice conditions: low, medium, and high concentrations. Parts of the image with cloud cover were cut out manually. The band $1(620-670 \mathrm{~nm})$ brightness (given as pixel values between 0 and 255) is high - typically greater than 220 for sea ice and less than 60 for open water. These two upper and lower values are used for scaling pixels between 100 and $0 \%$ ice concentration respectively. Pixels with intermediate brightness are assigned intermediate concentrations linearly. Pixels with a brightness above 220 and below 60 are assigned sea ice concentrations of 100 and $0 \%$ respectively. The $250 \mathrm{~m}$ spatial resolution is resampled to $1 \mathrm{~km}$ pixel resolution.

\subsection{Ice chart data for comparison}

The operational sea ice charts from the US National Ice Center (NIC) are used for comparison with the ESICR sea ice concentration. The ice charts, intended for aiding naviga- tion, are produced on a weekly basis covering all seasons and both the Southern and Northern Hemisphere, and the time series cover the entire climate record period except for the period December 1994 to January 2006 in the Southern Hemisphere. The ice charts used for comparison are a combination of three datasets: (1) the NIC ice charts for the Northern Hemisphere in 1972-2007, available at NSIDC in gridded format (Fetterer and Fowler, 2009), (2) the NIC ice charts for the Southern Hemisphere in 1973-1994, available at the NSIDC (Fetterer, 2006), and (3) the NIC ice charts for both hemispheres from 2006 to 2015, available from NIC.

The more recent ice charts are based partly on satellite Synthetic Aperture Radar (SAR) data, e.g. RADARSAT 1 since 1995 and ENVISAT since 2002, and various scatterometers together with visual/infrared line scanners, e.g. Advanced Very High Resolution Radiometer (AVHRR), MODIS, and Operational Linescan System (OLS), whenever possible for daylight and cloud cover conditions. Also, the passive microwave data from SMMR and SSM/I used in this reprocessing of ice concentrations have been extensively used for making the ice charts, in particular before the launch of wide-swath SAR instruments in 1995. In addition to the satellite data, ice charts are based on information from ships and aircraft reconnaissance. For an ice chart different sea ice categories are delineated manually by polygons and assigned a range of sea ice concentrations, thicknesses, type, etc. found within the polygon by an ice analyst. This information is represented on the satellite pixel grid by averaging the range of ice concentrations and other properties given within the polygon (Dedrick et al., 2001).

\section{Methodology}

\subsection{Dynamical tie points}

Tie points are typical signatures of ice and open water which are used in the ice concentration algorithms as a reference. The tie points are derived by selecting brightness temperatures from regions of known open water and ice.

During winter, in the consolidated pack ice well away from the ice edge, the ice concentration is very near $100 \%$. This has been established using high-resolution SAR data, ship observations, and by comparing the estimates from different ice concentration algorithms (Andersen et al., 2007). The apparent fluctuations in the derived ice concentration in the near- $100 \%$ ice regime are primarily attributed to variations in snow/ice surface emissivity and temperature around the tie-point signature and only secondarily to actual ice concentration fluctuations. In the marginal ice zone at intermediate ice concentrations and over open water the atmospheric emission and wind-induced water surface roughness and smearing dominates as error sources. The ice concentration algorithm sensitivity to atmospheric and surface emission is systematic, meaning that different algorithms with 
different sensitivity to atmospheric and surface emission can provide very different trends in sea ice extent on seasonal and decadal timescales (Andersen et al., 2007). This means not only that does the estimated sea ice extent has a climatic trend but also that the atmospheric and surface constituents affecting the microwave emission are changing. In an attempt to compensate for the influence of these artificial trends, the tie points are derived dynamically using a window of width \pm 15 days centred at the day of the actual sea ice concentration retrieval. It is assumed that ice concentrations greater than $95 \%$ from the NASA Team algorithm (Cavalieri et al., 1984) are in fact a representation of near$100 \%$ ice. The NASA Team algorithm has different sensitivities to artificial trends than the two algorithms used in combination here (Andersen et al., 2007). The ice tie point is the mean brightness temperature value of all data points with greater than $95 \%$ NASA Team sea ice concentration within the \pm 15 -days window. The static NASA Team tie points for SMMR are found in Gloersen et al. (1992) and for SSM/I the tie points are found in Andersen (1998). Geographically, the sea ice tie point is excluding data of both the SMMR and the SSM/I instruments polewards of $84^{\circ}$ for consistency between the SMMR and SSM/I periods. The open water tiepoint data were selected geographically along two belts in the Northern and Southern Hemisphere (between 53 and $75^{\circ} \mathrm{N}$ and between 65 and $80^{\circ} \mathrm{S}$ respectively). A land mask including the coastal zone and sea ice maximum extent climatology ensures open water data only.

There is no attempt to compensate explicitly for sensor drift or inter-sensor calibration differences (even though the SSM/I data have been intercalibrated by RSS) or possible biases in the NWP fields used for atmospheric noise reduction of the brightness temperatures. The dynamical tie-point method is in principle compensating for these problems in a consistent manner.

\subsection{Atmospheric noise reduction of the brightness temperatures using NWP data}

Using an emission model, the brightness temperatures are corrected for the influence of water vapour in the atmosphere and open water surface roughness caused by wind. The emission model used for atmospheric noise reduction of the SMMR brightness temperatures, $T_{\mathrm{b}}$, with NWP input is (Wentz, 1983)

$T_{\mathrm{b}}=f\left(T_{\mathrm{s}}, u^{*}, V, L, T_{\mathrm{a}}\right)$,

where $T_{\mathrm{S}}$ is the physical surface temperature, $u^{*}$ is the sea surface wind friction velocity, $V$ is the integrated atmospheric water vapour column, $L$ is the atmospheric liquid water column, and $T_{\mathrm{a}}$ is the surface (at $2 \mathrm{~m}$ ) air temperature. A similar model is used for the SSM/I and SSMIS data (Wentz, 1997). Over areas with both ice and water the influence of open water roughness on the brightness temperatures and the ice emissivity is scaled linearly with the ice concen- tration. The emissivity of ice is given by standard tie-point emissivity values and the total ice concentration is solved by iteration with a first guess of the ice concentration from the NASA Team algorithm (Cavalieri et al., 1984) with static tie points. The correction procedure is described in detail in Andersen et al. (2006b). The NWP model grid points are colocated with the satellite swath data in time (maximum $3 \mathrm{~h}$ ) and space using linear interpolation and a correction to the brightness temperatures using Eq. (1) is applied. The potential inconsistencies between the ERA-40 and the operational ECMWF models are minimized by the dynamical tie-point adjustment later in the processing and eventually the residual error is included in the error estimate.

The representation of atmospheric liquid water column in the NWP data is not suitable to use for brightness temperature correction because of the spatial and temporal variability of clouds, which is higher than the model grid cell size and model time step size. The brightness temperatures are therefore not corrected for the influence of atmospheric liquid water. Assuming a neutral atmospheric temperature profile, the wind speed at $10 \mathrm{~m}$, given by the numerical weather prediction model, is converted to the surface friction velocity using the factor 0.047 for use in the SMMR radiative transfer model. The other NWP variables are used directly.

\subsection{The ice concentration algorithm}

The analysis of atmospheric sensitivity in Andersen et al. (2006b) showed that the Comiso Bootstrap frequencymode (CF) algorithm (Comiso, 1986; Comiso et al., 1997) had the lowest sensitivity to atmospheric noise at low ice concentrations. Furthermore, the comparison to high-resolution SAR imagery in Andersen et al. (2007) indicated that among the algorithms using 19 and $37 \mathrm{GHz}$ channels available on both SMMR and SSM/I-SSMIS, the Bristol algorithm (Smith, 1996) had the lowest sensitivity to ice surface emissivity variability. In addition the Bristol algorithm had low sensitivity to atmospheric emission in particular at high ice concentrations.

Consequently, we use a combination of the Bristol algorithm and the CF algorithm - a so-called hybrid algorithm.

The CF algorithm uses $T_{19 \mathrm{v}}$ and $T_{37 \mathrm{v}}$. The algorithm assumes only two surface types: ice and open water. The linear relationship yields the following formulation for the total sea ice concentration, ic:

$\mathrm{ic}_{\text {Bootstrap }}=\left(T_{\mathrm{b}}-T_{\mathrm{b}}^{\mathrm{W}}\right) /\left(T_{\mathrm{b}}^{\mathrm{I}}+T_{\mathrm{b}}^{\mathrm{W}}\right)$,

where $T_{\mathrm{b}}$ is the measured brightness temperature, $T_{\mathrm{b}}^{\mathrm{W}}$ is the open water tie point, and $T_{\mathrm{b}}^{\mathrm{I}}$ is the ice tie point.

The Bristol algorithm (Smith, 1996) is conceptually similar to the Bootstrap algorithm. In a three-dimensional scatter plot spanned by $T_{19 \mathrm{v}}, T_{37 \mathrm{v}}$, and $T_{37 \mathrm{~h}}$ the ice points tend to fit a plane surface. The only difference to the Bootstrap algorithm is that instead of viewing the data in the $T_{19 \mathrm{v}}, T_{37 \mathrm{v}}$ space, the Bristol algorithm views the data perpendicular to 
the data plane that contains both the ice line and the water tie point, i.e. in a transformed coordinate system:

1. axis : $T_{37 \mathrm{v}}+1.045 T_{37 \mathrm{~h}}+0.525 T_{19 \mathrm{v}}$,

2. axis : $0.9164 T_{19 \mathrm{v}}-T_{37 \mathrm{v}}+0.4965 T_{37 \mathrm{~h}}$.

The remaining analysis is identical to the Bootstrap algorithm.

The Bootstrap algorithm is used over open water and the Bristol algorithm is used over ice. At intermediate concentrations up to $40 \%$ (from the Bootstrap ice concentration estimate) the ice concentration is an average weighted linearly between the two algorithms, i.e.

$\mathrm{ic}=(1-\mathrm{wc}) \cdot \mathrm{ic}_{\mathrm{Bristol}}+\mathrm{wc} \cdot \mathrm{ic}_{\mathrm{Bootstrap}}$,

where

$\mathrm{wc}=\left(\left|t-\mathrm{ic}_{\text {Bootstrap }}\right|+t-\mathrm{ic}_{\text {Bootstrap }}\right) /(2 \cdot t)$,

where $t$ is the threshold of $40 \%$.

\subsection{The sea ice concentration uncertainties}

The uncertainties described in the following sections are generally independent and the squared sum of the two estimated components of uncertainty is assumed to represent the total uncertainty squared. Each of the components is quantified as the standard deviation (SD) of sea ice concentration. The tie-point uncertainty $\varepsilon_{\text {tie point }}$, including residual atmospheric noise, sensor noise, and ice surface emissivity variability, is derived from measurements as the first component of uncertainty. The representativeness error, $\varepsilon_{\text {smear }}$, is simulated using a model as the second component of uncertainty, i.e.

$\varepsilon_{\text {total }}^{2}=\varepsilon_{\text {tie point }}^{2}+\varepsilon_{\text {smear }}^{2}$.

In addition to these two sea ice concentration uncertainty components there is the geolocation error. It occurs when the satellite is not exactly oriented (Poe et al., 2008). Simulations show that because of the large footprints (see next section for footprint sizes) compared to the typical geolocation errors of the SSM/I (about $\pm 5 \mathrm{~km}$, Hollinger et al., 1990), the ice concentration uncertainty due to geolocation errors is small and neglected here. There may be regions along the ice edge and along coastlines where the geolocation errors may be significant. However, we have not been able to include these errors in the sea ice concentration uncertainty estimate.

\subsubsection{First component: instrument noise, algorithm, and tie-point uncertainties}

Both the water surface and ice surface emissivity variability and emission and scattering in the atmosphere affect the brightness temperatures and the computed ice concentrations. To reduce the uncertainties due to atmospheric noise, the brightness temperatures are corrected using NWP data for atmospheric water vapour, near-surface air temperature, and open water roughness caused by wind. The remaining tiepoint uncertainties are given as the tie-point ice concentration standard deviation in regions with open water or $100 \%$ ice.

Random instrument noise also results in ice concentration uncertainties. The SSM/I instrument noise results in an ice concentration uncertainty of $1.4 \%$ for the Bristol algorithm and $1.7 \%$ for the Bootstrap algorithm in frequency mode (Andersen et al., 2006a). Systematic sensor drift is critical issue for ice concentration algorithms using static tie points. Here we use inter-sensor calibration and dynamical tie points intended for alleviating problems with sensor drift.

\subsubsection{Second component: the representativeness error}

Footprint sizes for the channels used for ice concentration mapping are uneven and range from about $50-70 \mathrm{~km}$ for the $19 \mathrm{GHz}$ channels to about $30 \mathrm{~km}$ for the $37 \mathrm{GHz}$ channels. The ice concentration data are normally represented on a finer grid (typically 12.5 or $25 \mathrm{~km}$ ) than the sensor footprint sizes $(30-70 \mathrm{~km})$. This effect is called smearing. The combination of footprints of uneven size in the ice concentration algorithm results in an additional smearing effect. This we call the footprint mismatch error. The smearing and the footprint mismatch error cannot be estimated separately. However, the combined error can be estimated if all other error sources and the ice cover reference are known a priori. It can also be simulated using high-resolution ice concentration reference data and a model for the satellite measurement footprint patterns. Here we use the model.

The smearing simulation model uses high-resolution brightness temperature input to compute the brightness temperatures as would be measured by the coarse-resolution radiometers on board the satellite. The high-resolution input is compared to the coarse-resolution output and realizations of ice concentrations in the hybrid sea ice concentration algorithm.

Reference SIC is derived from the brightness of cloud-free MODIS scenes resampled to $1 \mathrm{~km} \times 1 \mathrm{~km}$ pixel size described in Sect. 1.4. The MODIS pixel brightness across the image may vary slightly as a function of solar angle and albedo (snow type and sea ice type), leading to uncertainties in the derived ice concentration. However, here it is the reference and it does in fact provide a realistic spatial distribution of ice at the right scale for input to the model and as a reference for comparison. Each of these $1 \mathrm{~km} \times 1 \mathrm{~km}$ ice concentration pixels is assigned a microwave brightness temperature using standard tie points (Comiso et al., 1997) and linear mixing between 0 and $100 \%$. For each $1 \mathrm{~km} \times 1 \mathrm{~km}$ brightness temperature pixel elliptical Gaussian-shaped antenna patterns (Drusch et al., 1999) are used to simulate brightness temperatures at $19 \mathrm{v}$ and $19 \mathrm{~h}$ and $37 \mathrm{v}$ and $37 \mathrm{~h}$ as it would be measured with SMMR and SSM/I or SSMIS on the satellite. The simulations of brightness temperatures are used as input 
Table 2. The SD of the difference between the simulated SSM/ISSMIS satellite ice concentration and the reference ice concentration resampled to different grid resolutions in percent.

\begin{tabular}{lcccccc}
\hline & $1 \mathrm{~km}$ & $5 \mathrm{~km}$ & $10 \mathrm{~km}$ & $12 \mathrm{~km}$ & $25 \mathrm{~km}$ & $50 \mathrm{~km}$ \\
\hline CF & 18 & 16 & 14 & 13 & 10 & 7 \\
Bristol & 17 & 15 & 13 & 12 & 10 & 6 \\
OSISAF & 17 & 15 & 13 & 12 & 9 & 6 \\
\hline
\end{tabular}

to the $\mathrm{CF}$ and Bristol algorithms using standard tie points. The resulting ice concentration estimate is then compared to the ice concentration reference from MODIS sampled to different resolutions, i.e. $1,5,10,12,25$, and $50 \mathrm{~km}$ (see Table 2). The SD between the truth at a certain pixel resolution and the simulated satellite image is the smearing uncertainty. The smearing uncertainty is assumed uniform between $0 \%+\varepsilon_{\text {tiepoint }}$ and $100 \%-\varepsilon$ tiepoint. At 0 and $100 \%$ it is zero. Table 2 shows the smearing uncertainty for the $\mathrm{CF}$, Bristol, and average hybrid OSISAF algorithm SDs at different grid resolutions. The final grid resolution of the ESICR obtained with the OSISAF algorithm is $12 \mathrm{~km}$ and has a smearing uncertainty of $12 \%$ (Table 2). The smearing uncertainty is nearly the same for the $\mathrm{CF}$ and the Bristol algorithms.

The MODIS image used for estimating the smearing uncertainty is shown in Fig. 1. The image has regions of open water, intermediate concentrations, and $100 \%$ ice cover. The simulated SSM/I sea ice concentration using Fig. 1 as input to the hybrid OSISAF algorithm is shown in Fig. 2.

\subsubsection{The sea ice concentration uncertainty algorithm}

The representativeness uncertainty is computed as a function of ice concentration using a model. The other error sources are computed using the hemispheric standard deviation of the ice concentration estimates over open water and over near$100 \%$ ice respectively. The ice concentration algorithm provides ice concentrations which are greater than $100 \%$ and less than $0 \%$ because of the natural variability of the measured brightness temperatures around the ice and open water tie points. These unphysical concentrations are truncated in the processing. ic is the ice concentration calculated by the algorithm and $\alpha$ is the truncated ice concentration (constrained to the interval 0-100\%):

if ic $\leq 0$ then $\alpha=0$,

if $0<$ ic $<1$ then $\alpha=$ ic,

if ic $\geq 1$ then $\alpha=1$.

Using Eq. (2) and assuming the uncertainty for the ice and water part is independent leads to a total tie-point uncertainty

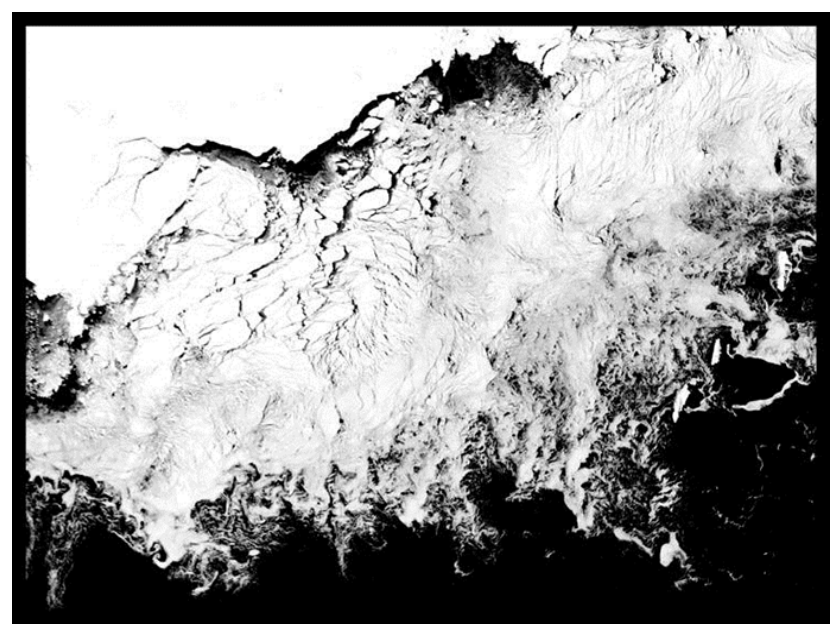

Figure 1. The $1 \mathrm{~km}$ cloud-free MODIS image $3000 \mathrm{~km} \times 2200 \mathrm{~km}$. The scene is situated north of McMurdo Station and east of the Ross Sea, Antarctica. Ice concentrations between 0\% (black) and $100 \%$ (white). The scene is recorded at 03:30 UTC 24 February 2008 by the Aqua satellite. The scene centre is at $69.5^{\circ} \mathrm{S}, 165^{\circ} \mathrm{W}$.

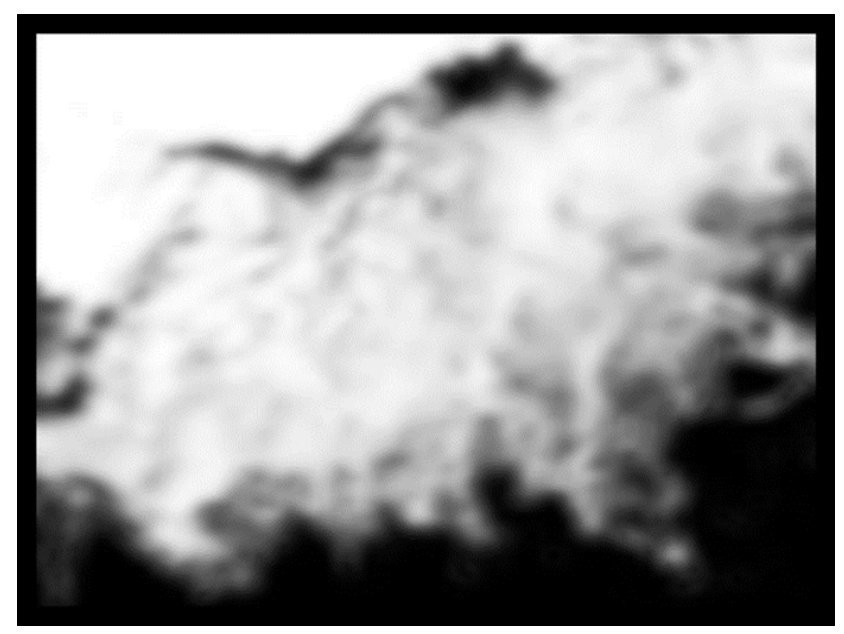

Figure 2. The simulated ice concentrations using the SSM/I sensor specifications and the OSISAF hybrid ice concentration algorithm and the data in Fig. 1 as input. Ice concentrations between $0 \%$ (black) and $100 \%$ (white).

of

$$
\begin{aligned}
& \varepsilon_{\text {tie point }}(\alpha(\text { ic }))=\sqrt{(1-\alpha(\text { ic }))^{2} \varepsilon_{\text {water }}^{2}+\alpha^{2}(\text { ic }) \varepsilon_{\text {ice }}^{2}}, \\
& \text { where } \varepsilon_{\text {water }}=\varepsilon\left(\operatorname{IC}\left(P_{\text {water }}\right)\right) .
\end{aligned}
$$

Open water is determined from open water measurements near the ice edge, IC is the functional mapping of the ice concentration algorithm, and $P_{\text {water }}$ denotes the set of open water swath pixels for all swaths (used for calculating the daily product). 
The SD of the ice concentrations where NASA Team ice concentrations are greater than $95 \%$ is

$\varepsilon_{\text {ice }}=\varepsilon\left(\operatorname{IC}\left(P_{\mathrm{NT}>0.95}\right)\right)$.

The ice concentration uncertainty is a function of sea ice concentration (Fig. 3) where the total uncertainty squared is the sum of the two uncertainty components squared (see Eq. 5). The smearing uncertainty is zero for open water and for $100 \%$ ice and at these two points on the curve the total uncertainty equals the tie-point uncertainty (including sensor and residual atmospheric noise) for open water and ice respectively (see Eqs. 6 and 7). The smearing uncertainty reaches a maximum at intermediate concentrations between $\left(0 \%+\varepsilon_{\text {tiepoint }}\right)$ and $\left(100 \%-\varepsilon_{\text {tiepoint }}\right)$. Because the sea ice concentration is provided on a relatively fine grid of about $12.5 \mathrm{~km}$ compared to the actual resolution of the sensor the smearing uncertainty is the component which is dominating the total uncertainty for most of the sea ice concentration range (Fig. 3). When the grid resolution is comparable to the footprint size of the sensor, i.e. in our case about $50 \mathrm{~km}$, the smearing uncertainty (see Table 2) becomes comparable in magnitude to the tie-point uncertainty which is where the total uncertainty is at a minimum.

\subsection{From level 2 swath projection data to interpolated level 4 maps}

The transition from level 2 swath projection data to the final level 4 daily predefined EASE grid includes the gridding of the swath data, the filtering of coast line grid cells, the maximum ice extent masking and spatial and temporal interpolation of data gaps. Whenever a pixel is altered by any of these processing steps it is indicated with a flag value in the product file.

The time window of $24 \mathrm{~h}$ is centred at 12:00 UTC. The ice concentration swath data are averaged for each grid cell using the simple weighting function:

weight $=1-0.3 \cdot($ dist/inflrad $)$,

where dist is the distance between the data point centre and the grid cell centre and inflrad is the radius of influence $(18 \mathrm{~km})$. All data from overlapping missions are included in the gridding except the overlap between SMMR and SSM/I. Only the SSM/I data are used during the overlap of 1.5 months between SMMR and SSM/I.

\subsubsection{Statistical filtering of ice concentration near the coastline}

Due to the coarse spatial resolution of the radiometers the data may be influenced by land up to $70 \mathrm{~km}$ from the coastline. The emissivity of land along the coastline is comparable to sea ice emissivity and much higher than water emissivity. This means that in the coastal zone, if there is open water or

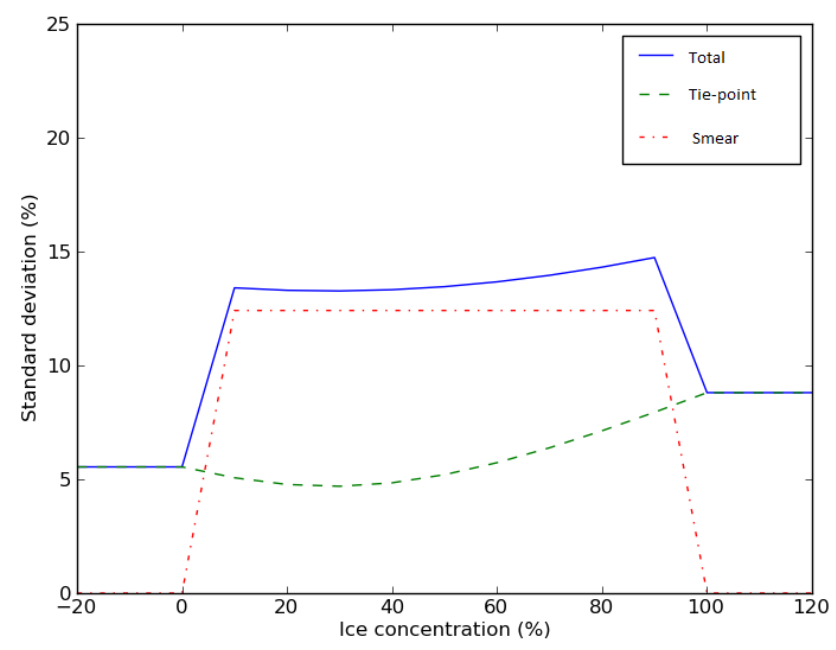

Figure 3. The total uncertainty in blue and its two components: the smearing uncertainty in red and the tie-point uncertainty in green as a function of ice concentration.

intermediate concentrations, the sea ice concentration will be overestimated. The statistical method which is described by Cavalieri et al. (1999) is used for filtering the ice concentration near the coast.

\subsubsection{Climatological maximum sea ice extent masking}

Occasionally spurious sea ice is detected in open water regions far from the ice edge due to atmospheric noise affecting the ice concentration estimate. These spurious sea ice detections are masked out using the monthly maximum extent climatology by the NSIDC (http://nsidc.org/data/smmr_ssmi_ ancillary/ocean_masks.html). Within a month the position of the daily sea ice edge can fluctuate substantially and it might cross the border of the maximum extent climatology used. Therefore, in order to not generally limit the ice extent to this climatology and allow detection of real sea ice also outside of the climatology, we added a zone of additional $100 \mathrm{~km}$ into the open water.

\subsubsection{Level 4: gap filling by spatial and temporal interpolation}

Grid cells with missing data are filled with interpolated values in the level 4 processing and the affected pixels are flagged. Daily data coverage is never complete due to the observation gap near the North Pole (see Sects. 1.1 and 1.2) and occasionally there are missing scan lines and missing orbits. Spatial interpolation can fill small gaps, e.g. one or two missing scan lines but it is deceiving when large areas are missing and filled with interpolated values. To overcome this issue, and also implement a general approach for all cases, both temporal and spatial interpolation is used. 
The weighting parameters are computed as follows:

$w_{i, j}^{D}=1 /\left(\sigma_{i, j}^{D}\right)^{2}\left(2 N_{\max }+1\right)$,

$W^{D}(k l ; i j)=1 /\left(\sigma_{k, l}^{D}\right)^{2} \times \exp \left(-0.5\left(\frac{\Delta(k, l ; i, j)}{R_{i, j}}\right)^{2}\right)$,

where $\sigma$ is the standard deviation associated to each ice concentration estimate, $\Delta$ is the distance between a given $(k, l)$ neighbour and cell $(i, j)$, and $R$ is an autocorrelation radius. The spatial interpolation weight is thus based on an isotropic Gaussian distribution, and almost all $(>99.9 \%)$ of the interpolation weight is concentrated inside a $[-3 R ;+3 R] \times[-3 R ;+3 R] \mathrm{km}^{2}$ area, which translates into a $\left[-N_{\max } ;+N_{\max }\right] \times\left[-N_{\max } ;+N_{\max }\right]$ grid cells squared area. It was found by testing that $R$ is proportional to the absolute latitude in degrees, i.e. $R=$ latitude of $(i, j)$.

The interpolation on a given date, $D$, uses data from the day before and the day after, i.e. $D-1$ and $D+1$.

The interpolated value at grid cell $(\mathrm{i}, \mathrm{j})$ for day $D$ is given by

$$
\begin{aligned}
& X_{i, j}^{D} \\
& =K\left(w_{i, j}^{D-1} X_{i, j}^{D-1}+w_{i, j}^{D+1} X_{i, j}^{D+1}+\Sigma_{k, l} W^{D}(k l ; i j) X_{k, l}^{D}\right),
\end{aligned}
$$

where $X$ is the sea ice concentration value and $K$ is a normalizing factor given by

$w_{i, j}^{D-1}+w_{i, j}^{D+1}+\Sigma_{k, l} W^{D}(k l ; i j)=1 / k$.

The spatial interpolation from neighbours of cell $(i, j)$ in Eq. (13) is only using values from date $D$, while the temporal interpolation is concerned with the value from the exact $(i, j)$ cell and from dates $D-1$ and $D+1$. This ensures that the interpolation will be efficient in the two following extreme scenarios. (1) In a region where we never have satellite observations, e.g. the data coverage gap near the North Pole, the spatial interpolation term will be the only contribution. (2) Conversely, in the case of several missing swaths on day $D$ only (nominal coverage on $D-1$ and $D+1$ ), the interpolated values will be computed from the previous and next days, taking advantage of the persistence of sea ice concentration over relatively short periods. The interpolation for intermediate cases (when both spatial and temporal neighbours exist) is a compromise of those extreme situations.

For the SMMR, which was operated every second day, the temporal interpolation is $D-2$ and $D+2$ instead of $D-1$ and $D+1$ for SSM/I and SSMIS.

\section{Results and discussion}

We compared the ESICR to sea ice charts for reference during the period from October 1978 to April 2015 in both hemispheres. There is a gap in the comparison in the Southern
Hemisphere between 1994 and 2006 (see Sect. 1.5). The overlap period during July and August 1987 between the SMMR and the SSM/I instruments is analysed in more detail in Sect. 3.2.

The ice charts are produced to support ship and offshore operations and not to monitor sea ice as a climate parameter. However, they do well in identifying areas of open water and ice and the comparison does in fact reveal trends in the ESICR noise levels.

\subsection{The ice concentration comparison to sea ice charts}

The NIC ice charts and the ESICR are gridded onto the $12.5 \mathrm{~km}$ EASE grid and compared pixel by pixel. The total concentration in the ice chart is given as the average of the range of sea ice concentrations, e.g. 10-30\%, describing the variability within each ice chart polygon. The bias and SD between ice chart and the ice concentration are computed for ice (ice chart concentration greater than $0 \%$ ) and for open water (ice chart concentration equal to zero).

The ESICR ice concentration is higher than the ice chart over open water by 5-15\% in the Northern Hemisphere (Fig. 4). This is due to the fact that the radiometer ice concentration is affected by atmospheric noise and smearing near the ice edge, which increases the ESICR ice concentration above zero, while the ice charts have a nominal value of zero over open water. Actually, the mean open water ESICR ice concentration is zero at swath level (level 2). However, all negative ice concentration estimates are truncated to zero, which leaves the small positive bias in the final product (level 4). The uncorrected noise from, in particular, cloud liquid water, but also atmospheric water vapour and wind over open water, gives a positive bias in the ESICR ice concentrations. The SMMR to SSM/I transition in 1987 is hardly seen even though the SSM/I $19.35 \mathrm{GHz}$ is affected more by water vapour than the $18.0 \mathrm{GHz}$ SMMR instrument. Apparently not all the noise due to atmospheric water vapour and wind is removed successfully in the brightness temperature correction scheme and there is a trend from the beginning to the end of the comparison. This trend is interpreted as a gradual improvement of the NWP data, especially since 2002 when the operational model is used instead of ERA-40. Trends in the amount of cloud liquid water, which is not included in the $\mathrm{Tb}$ correction, could also result in the trend which is seen in Fig. 4. The ice bias has a clear seasonal cycle and a negative winter bias around -5 to $-15 \%$. The negative summer sea ice bias sometimes reaches $-20 \%$.

Both the standard deviation of open water and ice has a clear seasonal cycle with higher standard deviations during summer than during winter (Fig. 5) and the standard deviation of open water has a decreasing trend during the latter part of the record. This could be a result of higher-quality wind and water vapour data in the recent part of the ERA-40 reanalysis and in the operational ECMWF model used since 2002. 


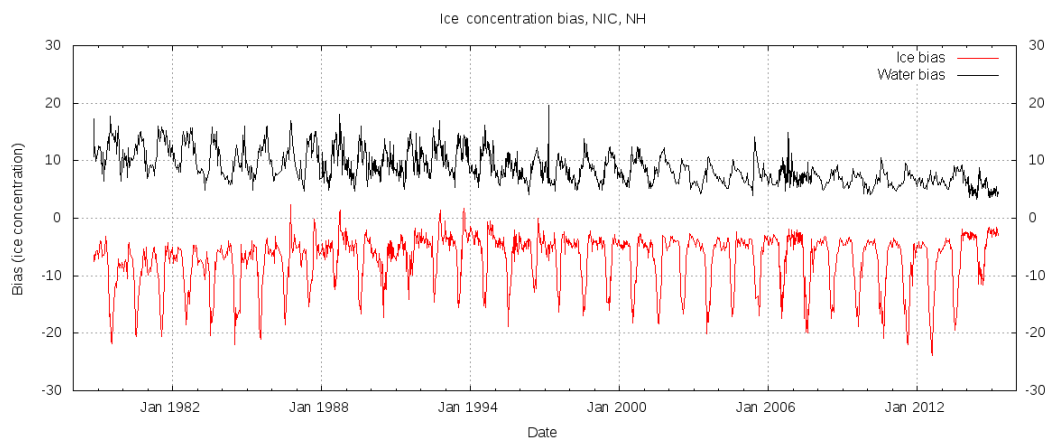

Figure 4. The Arctic ESICR-NIC ice chart mean difference (bias) for areas of ice in red and for areas of open water in black.

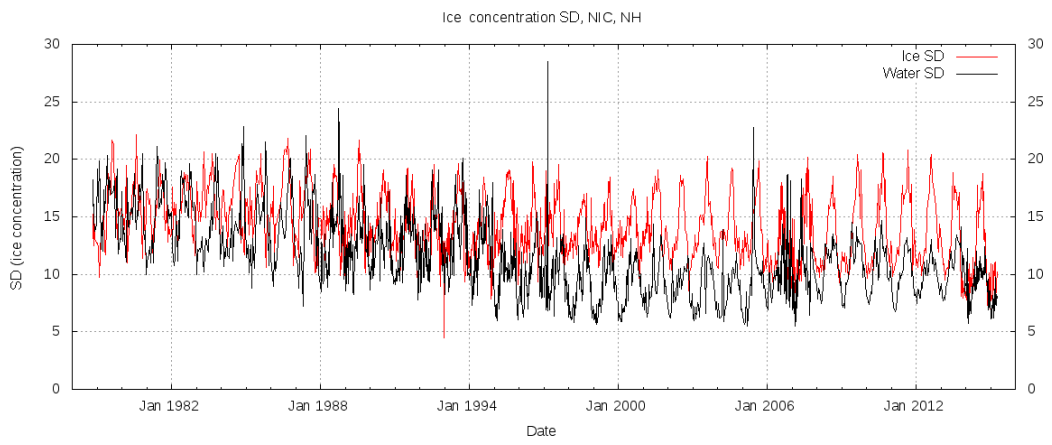

Figure 5. The Arctic ESICR-NIC ice chart standard deviation of the difference for areas of ice in red and for areas of open water in black.

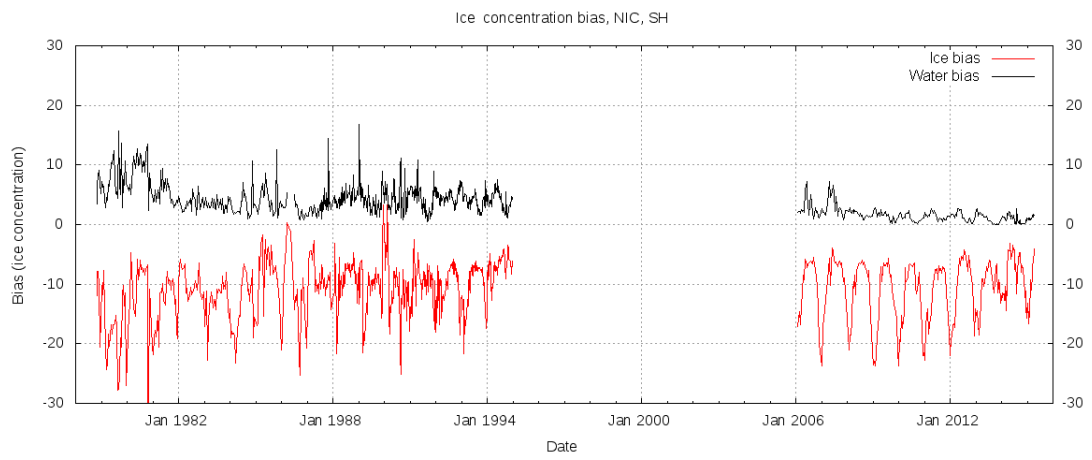

Figure 6. The Antarctic ESICR-NIC ice chart mean difference (bias) for areas of ice in red and for areas of open water in black. No ice charts were available to us from 1994 to 2006.

There is also a small positive bias over open water in the Southern Hemisphere due to the truncation of spurious sub-zero ice concentrations in the ESICR (Fig. 6). Over ice, the ESICR and NIC ice chart difference is negative around $-10 \%$ during Antarctic winter. During the Antarctic summer the difference over ice is near $-20 \%$.

The standard deviation of the difference between the ESICR and the NIC ice charts (Fig. 7) is higher and has more interannual variability in Antarctica than in the Arctic, except for the comparison over open water where the difference is between 0 and $5 \%$ from 2006 onwards.

\subsection{The SMMR and SSM/I overlap}

The overlap period between SMMR and SSM/I during July and August 1987 is short because 15 days prior and after the actual date are needed in order to establish the tie points properly. Subtracting 15 days in each end of the overlap period leaves only a few days where the tie points are fully established. For the periods where the tie points are not fully developed the tie points for SMMR and for SSM/I cover different time periods and they are therefore expected to differ. In the Northern Hemisphere (Fig. 8) the bias is below $4 \%$ and this may be due to melt ponds with diurnal variability in 


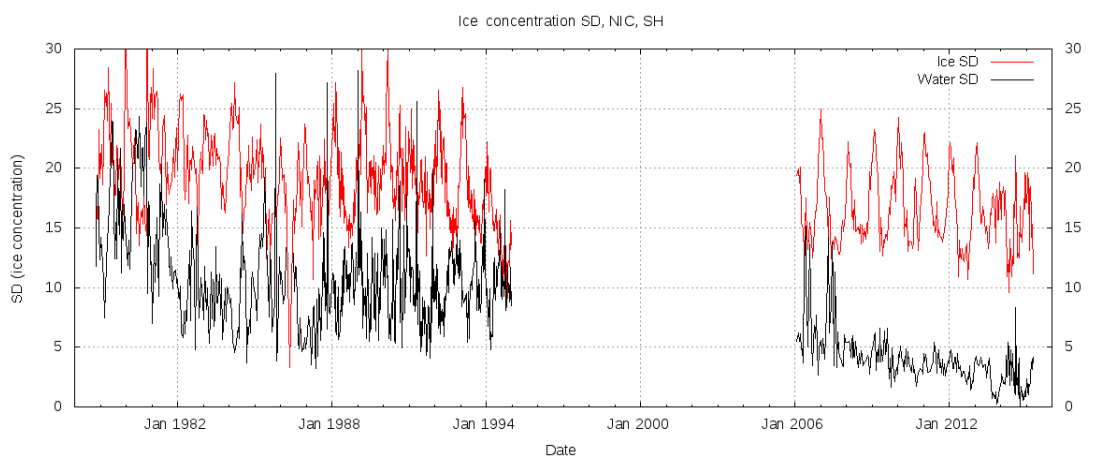

Figure 7. The ESICR and NIC ice chart standard deviation of the difference around Antarctica. The red curve is for ice and the black curve is for water. No ice charts were available to us from 1994 to 2006.

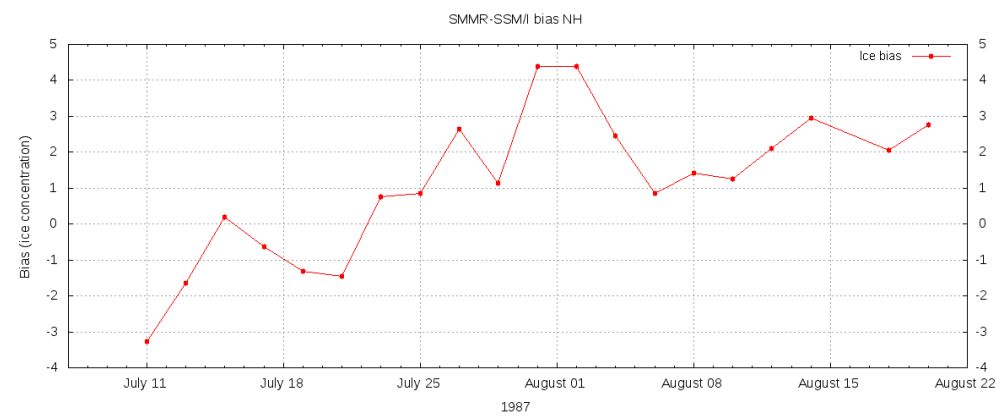

Figure 8. The overlapping SMMR-SSM/I difference in the Arctic during summer melt. The red curve shows the ice bias.

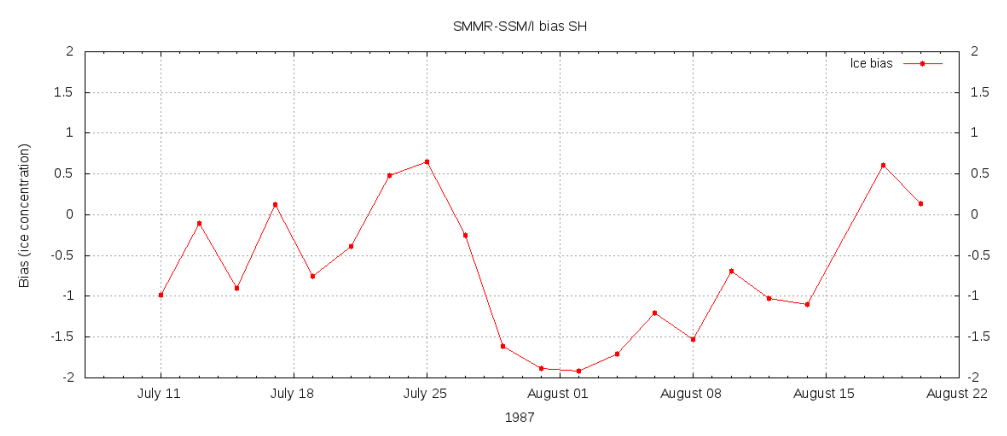

Figure 9. The overlapping SMMR-SSM/I difference around Antarctica during austral winter. The red curve shows the ice bias.

their signatures and the two instruments' different orbits and data coverage.

The SMMR and SSM/I overlap period coincides with the ice maximum in the Southern Hemisphere, which is ideal for comparison (Fig. 9), and the bias is even smaller than in the Northern Hemisphere (less than $2 \%$ ). Inspecting the differences geographically (not shown) indicates that when environmental conditions have not changed significantly during SMMR and SSM/I passes the SSM/I is slightly higher over open water while over ice the two estimates are close to each other.

\subsection{Ice chart and ESICR comparison discussion}

The uncertainties in the NIC sea ice charts are described in Dedrick et al. (2001). Another study of the differences between ice charts from Greenland and Norwegian ice centres covering the same region shows relatively large (up to $30 \%$ ) discrepancies in ice concentration SD of the difference especially at intermediate concentrations (Breivik et al., 2015). Compared to microwave radiometer ice concentrations (the OSISAF operational algorithm in Andersen et al., 2006b) the ice concentration in Greenland ice charts is systematically about $30 \%$ higher at intermediate concentrations. Trials with the ice concentration model described in Sect. 2.5.3 show 
that the estimates from most sea ice concentration algorithms including the Bootstrap and the Bristol agree very well with the actual ice concentration and that there are very small differences between the overall response of different algorithms (ice concentration differences $<1 \%$ on $1000 \mathrm{~km}$ scale not including noise). The different algorithms thus yield the same ice concentrations given the same tie points and brightness temperature input. We did not find a similar investigation comparing NIC and other overlapping and coincident ice charts. However, we note that the methodology for making the Greenland, Norwegian, and NIC ice charts is similar.

The bias between ice charts and radiometer ice concentrations at intermediate concentrations, i.e. near the ice edge and in the marginal ice zone, can be caused by two effects: (1) the estimated radiometer ice concentrations are lower than real ice concentration for new ice and lower when the surface is melting or refrozen after melting. Both new ice and melting/refreezing is abundant in regions with intermediate ice concentrations and this will thus lead to the radiometer underestimating the real ice concentration. A hybrid algorithm such as OSISAF mitigates biases due to melting/refreezing to some extent but usage of hemispheric tie points cannot account for existing regional differences in melt progress. (2) The ice charts' ice concentration is a subjective estimate which is made for the safety of navigation and an overestimation of the ice concentration in the ice chart, particularly near the ice edge and in the marginal ice zone, might stem from "better-safe-than-sorry" practices within the ice charting community.

\subsection{The ESICR comparison to the NSIDC Sea Ice Index monthly sea ice extent}

The differences between sea ice climate data records from the same set of satellite microwave radiometer data (SMMR, SSM/I and SSMIS) are primarily due to different spatial resolution, land masks and land spill over correction methodologies, and different ice concentration thresholds for delineating the sea ice extent. The choice of sea ice concentration algorithms and atmospheric correction methods also influences the sea ice extent estimate (Kern et al., 2014). The NSIDC sea ice extent uses the NASA Team sea ice concentration algorithm and a $15 \%$ threshold for delineating the sea ice extent. The land masks are similar to the ones used in the ESICR. The mean monthly sea ice extent from the NSIDC is shown together with the ESICR in Table $3 a$ and $b$ for comparison. In the Arctic (Table 3a) the differences between the NSIDC and the ESICR data records are small (less than 0.4 million $\mathrm{km}^{2}$ ). In the Southern Hemisphere the differences are up to 1.5 million $\mathrm{km}^{2}$ (in December). These differences in sea ice extent are due to the different sea ice concentration thresholds which are used for delineating the ice extent in the ESICR $(30 \%)$ and the NSIDC (15\%), the different methods for atmospheric correction, the different sea ice concentra- tion algorithms, and the different tie points which are used for generating the two datasets (Fetterer et al., 2016).

\subsection{The ESICR metrics}

In the following we give examples of the ESICR dataset for estimating sea ice climate statistics and trends. The applied climate period here is the full length of the ESICR from October 1978 to the end of 2014. We give examples for both hemispheres.

In this context, the sea ice extent is defined as the area covered by sea ice within the ice edge. The ice edge is defined as the $30 \%$ contour. Ice concentrations greater than $30 \%$ are considered as ice covered while concentrations less than $30 \%$ are considered open water. This threshold is higher than e.g. the $15 \%$ threshold used in Parkinson and Cavalieri (2008). The higher threshold is needed here because we are not using weather filters in the processing and therefore there may be more noise over open water resulting in an unwanted overestimation of the ice extent. The noise level over open water depends on the success of the Tb correction, i.e. partly on the quality of the NWP data, and the levels of cloud liquid water, which we cannot yet correct for.

For the Arctic there is a negative trend in the monthly mean extent for all months of the year (Table 3a). The negative slope is largest in September $\left(-94000 \pm 9700 \mathrm{~km}^{2} \mathrm{yr}^{-1}\right)$ and smallest in May $\left(-32000 \pm 4600 \mathrm{~km}^{2} \mathrm{yr}^{-1}\right)$. For the Antarctic there is a positive trend in the monthly mean extent for all months of the year (Table $3 \mathrm{~b}$ ). The positive slope is largest in the months April, October, and December $\left(33000 \mathrm{~km}^{2} \mathrm{yr}^{-1}\right)$ and smallest in February $\left(13000 \pm 5400 \mathrm{~km}^{2} \mathrm{yr}^{-1}\right)$.

The mean sea ice extent for the Arctic for years 1979 through 2014 is shown in Fig. 10 together with the September 2012 sea ice extent. The lower two panels display the seasonal variability of the sea ice extent and the long-term mean monthly sea ice extent in March and in September, the months with maximum and minimum extent respectively. In this panel we have included the extent for the most recent 11 years of ESICR (2004-2014) for comparison. September 2012 was the lowest sea ice extent on record in the Arctic since beginning of the satellite era. Over the 35 years of ESICR there is a negative trend in sea ice extent for all months of the year with the largest negative trend during the summer and the beginning of autumn (July-October).

The mean sea ice extent for the Antarctic for years 1979 through 2014 is shown together with the September 2012 sea ice extent in Fig. 11. The lower two panels show the seasonal variability of the sea ice extent and the long-term mean monthly sea ice extent in March and in September. The sea ice extent has experienced an overall positive trend around Antarctica, especially along the ice edge in the Weddell and Ross Seas downstream of the northward branches of the cyclonic atmospheric circulation.

In order to assess the length of the ice season for a given pixel, the annual spatial distribution of dates of freeze-up and 
Table 3. (a) The mean monthly sea ice extent 1978-2014, long-term trend, and standard error of the trend in the Arctic. All figures are in millions of square kilometre. The right-hand column shows the mean monthly NSIDC Sea Ice Index Arctic sea ice extent (1978-2014) for comparison (Fetterer et al., 2016). (b) The mean monthly sea ice extent 1978-2014, trend, and standard error of the trend in the Antarctic. All figures are in millions of square kilometre. The right-hand column shows the mean monthly NSIDC Sea Ice Index Antarctic sea ice extent (1978-2014) for comparison (Fetterer et al., 2016).

\begin{tabular}{lcccc}
\hline Month & $\begin{array}{c}\text { Mean } \\
\left(10^{6} \mathrm{~km}^{2}\right)\end{array}$ & $\begin{array}{c}\text { Trend } \\
\left(10^{6} \mathrm{~km}^{2} \mathrm{yr}^{-1}\right)\end{array}$ & $\begin{array}{c}\text { Trend SE } \\
\left(10^{6} \mathrm{~km}^{2} \mathrm{yr}^{-1}\right)\end{array}$ & $\begin{array}{c}\text { NSIDC Sea Ice Index mean } \\
\left(10^{6} \mathrm{~km}^{2}\right)\end{array}$ \\
\hline January & 14.641 & -0.045 & 0.0040 & 14.589 \\
February & 15.505 & -0.045 & 0.0043 & 15.407 \\
March & 15.620 & -0.041 & 0.0042 & 15.572 \\
April & 14.772 & -0.036 & 0.0048 & 14.838 \\
May & 13.403 & -0.032 & 0.0046 & 13.434 \\
June & 11.899 & -0.053 & 0.0044 & 11.908 \\
July & 09.667 & -0.079 & 0.0060 & 09.641 \\
August & 07.458 & -0.084 & 0.0083 & 07.144 \\
September & 06.881 & -0.094 & 0.0097 & 06.395 \\
October & 09.053 & -0.077 & 0.0089 & 08.821 \\
November & 11.138 & -0.055 & 0.0052 & 10.983 \\
December & 13.241 & -0.044 & 0.0043 & 13.107 \\
\hline January & 04.566 & 0.022 & 0.0092 & 05.295 \\
February & 02.911 & 0.013 & 0.0054 & 03.148 \\
March & 04.105 & 0.022 & 0.0072 & 04.461 \\
April & 06.860 & 0.033 & 0.0099 & 07.459 \\
May & 10.135 & 0.032 & 0.0089 & 10.843 \\
June & 13.229 & 0.029 & 0.0072 & 14.018 \\
July & 15.622 & 0.022 & 0.0055 & 16.523 \\
August & 17.129 & 0.022 & 0.0059 & 18.214 \\
September & 17.684 & 0.029 & 0.0089 & 18.909 \\
October & 17.278 & 0.033 & 0.0070 & 18.460 \\
November & 15.164 & 0.020 & 0.0065 & 16.388 \\
December & 09.932 & 0.033 & 0.0115 & 1.412 \\
\hline
\end{tabular}

break-up were calculated using a simple methodology, the results of which are comparable to Parkinson (2014). The freeze-up date for a given point is defined as the date when the sea ice concentration exceeds $30 \%$ and remains so for at least 5 days. Similarly, the break-up date for a given point is defined as the date when the sea ice concentration falls from above to below $30 \%$ and remains so for at least 5 days.

Since the sea ice does not retreat and expand completely every year, not all areas experience the same number of freeze-ups and break-ups over an equal period of years. Therefore, some regions may experience relatively few freeze-ups and break-ups, thus reducing the confidence in the trend of the region. As a consequence, only areas having experienced more than six freeze-ups/break-ups are considered.

The open water days are calculated as the difference in days between freeze-up and break-up and the decadal trends in the open water days are shown in Fig. 12 for the Arctic and in Fig. 14 for the Antarctic.

In the Arctic, over the record of 35 years the number of open water days has been increasing by at least 60 days in the Davis Strait and in large parts of the Barents Sea. The ice season (the opposite of open water days) has been shortening consistently all over the Arctic except in the Bering Strait re- gion and the Greenland Sea (Fig. 12). The negative trend in the Greenland Sea is not significant and based on an insufficient number of data points. In fact, the large areas with new ice formation which used to characterize the ice cover in Greenland Sea have appeared rarely since 2000 (Tonboe and Toudal, 2005; Rogers and Hung, 2008). The shortening of the ice season in the Arctic in general is due both to a delay of the freeze-up and earlier break-up in combination (not shown). This is consistent with e.g. Close et al. (2015).

The significance of the trends in the number of open water days is shown in Figs. 13 and 15 for the Arctic and Antarctic, respectively, as a test of the null hypothesis, i.e. testing the probability of no trend. This means that a low probability indicates that the trend is in fact significant. It is noted that the trend is significant in most Arctic regions (Fig. 13). There is a negative decadal trend in the number of open water days around Antarctica in regions with a seasonal sea ice cover (Fig. 14), except in the Bellingshausen Sea/Amundsen Sea and the Indian Ocean. The trend is significant in large regions in the Weddell Sea and in the Ross Sea (Fig. 15). The negative trend in the number of open water days in the Ross and in the Weddell Seas indicates that the ice is staying longer in these areas now than before. 

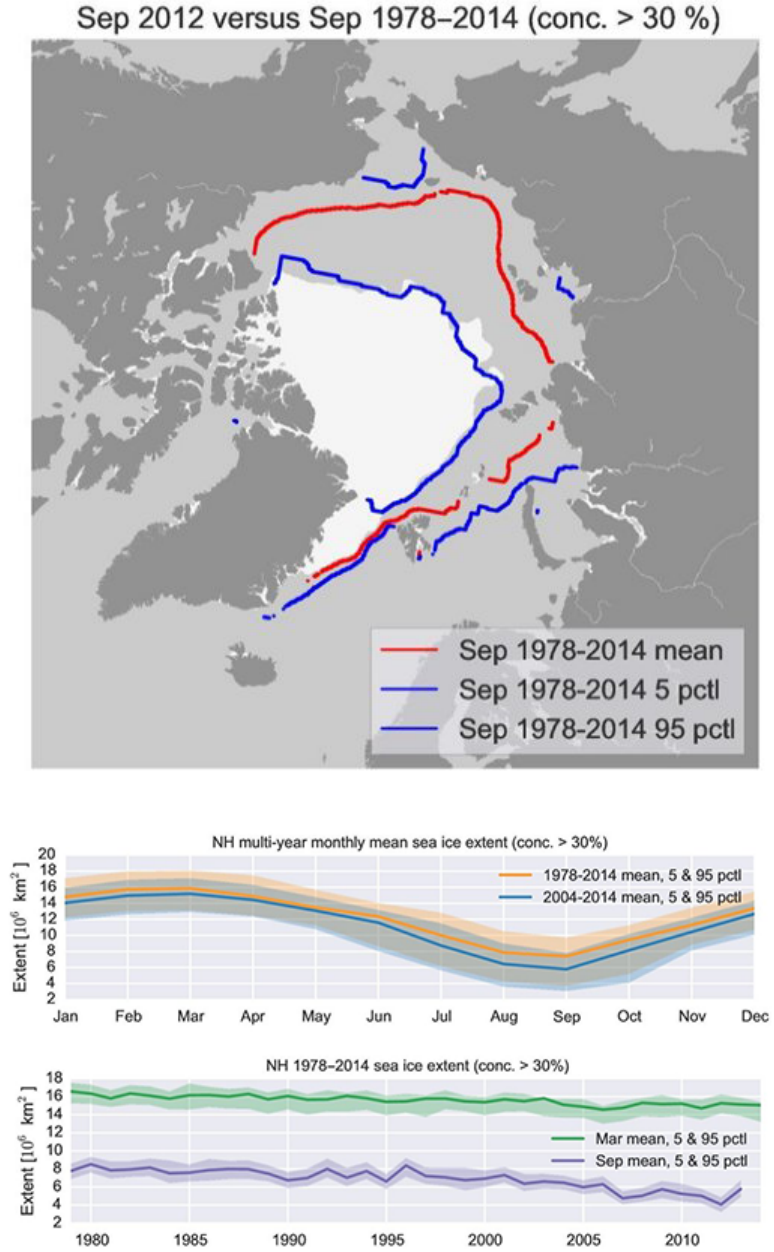

Figure 10. The upper panel: the September 2012 sea ice extent in the Arctic compared to the mean extent shown with the red line. The blue lines on either side of the mean extent line (red) are the 5 and 95 percentiles of ice extent. The lower two panels show the annual cycle of sea ice extent. The shaded areas are the 5 and $95 \%$ percentiles of the interannual and daily variability respectively. The lower panel show the long-term (1978-2014) Arctic sea ice extent near its maximum in March and near its minimum in September.

\section{Conclusions}

A sea ice climate record covering the period from autumn 1978 to the end of 2014 has been produced based on past satellite microwave radiometer data from SMMR, SSM/I, and SSMIS. The climate record has been produced according to four principles to ensure consistency and to minimize the sensitivity to noise sources:

1. Finding algorithms with low sensitivities to geophysical noise. Two algorithms have been selected in combination based on the evaluation in Andersen et al. (2007), the Bristol over ice, and the Bootstrap in frequency mode over open water. An independent evaluation of
Sep 2012 versus Sep 1978-2014 (conc. > 30 \%)
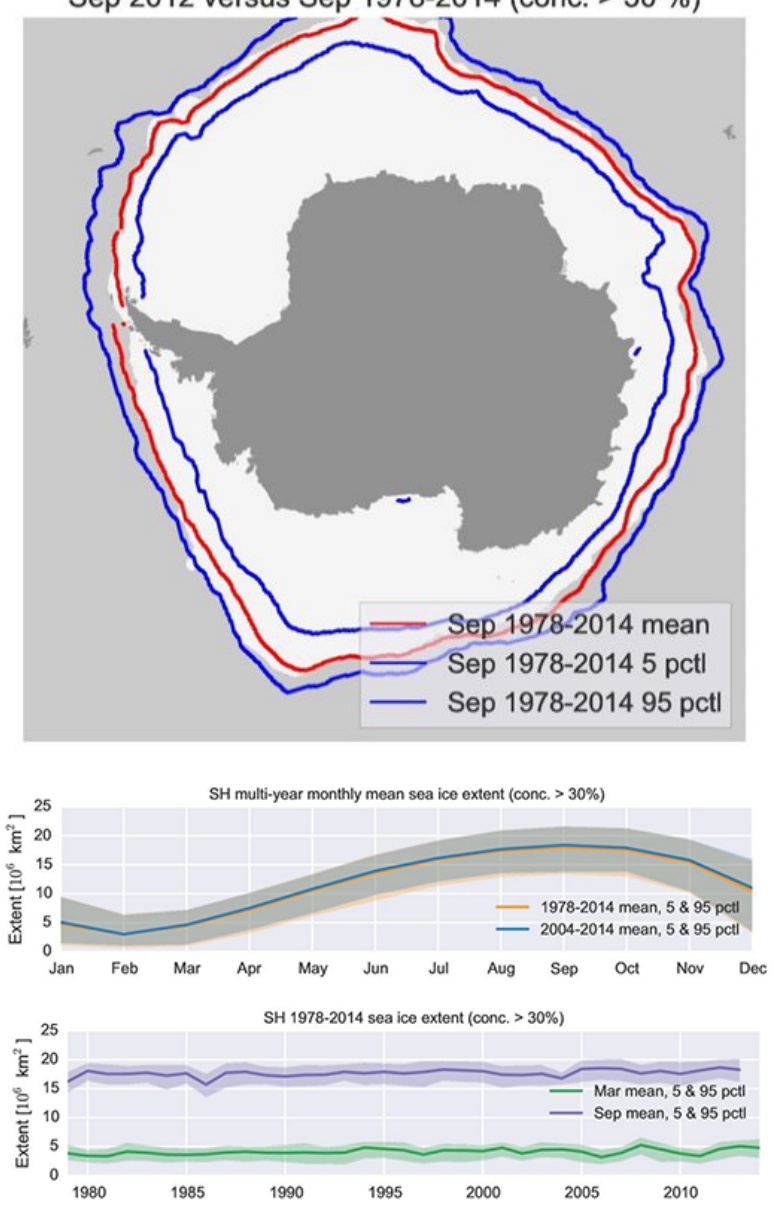

Figure 11. The upper panel: the September 2012 sea ice extent in the Antarctic compared to the mean extent shown with the red line. The blue lines on either side of the mean extent line are the 5 and 95 percentiles of ice extent. The lower two panels show the annual cycle of sea ice extent. The shaded areas are the 5 and $95 \%$ percentiles of the interannual and daily variability respectively. The lower panel show the long-term (1978-2014) Antarctic sea ice extent near its maximum in March and near its minimum in September.

algorithms in Ivanova et al. (2015) pointed at the same two algorithms.

2. Regional error reduction correcting the brightness temperatures for water vapour in the atmosphere and wind over open water. The scheme described in Andersen et al. (2006b) is used to reduce the noise over both ice and water.

3. Calibrate the algorithms to the actual ice and water signatures and sensor drift using dynamical tie points. The result of using dynamical tie points has been demonstrated here at the transition from SMMR to SSM/I with satisfactory results. In addition, we do not see any jumps at sensor transitions in the comparison to the independent ice chart dataset. 


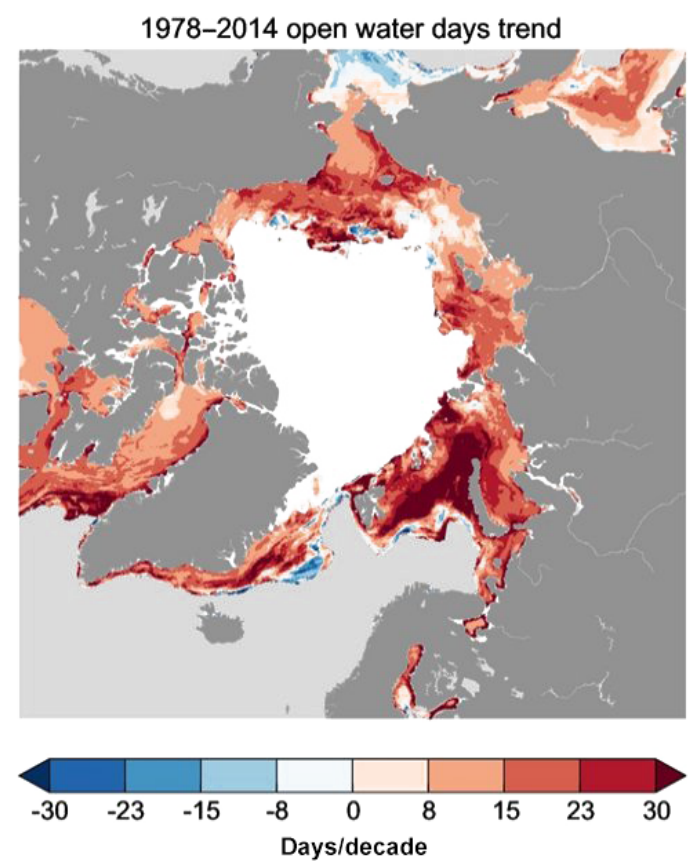

Figure 12. The linear trend in open water days in the Arctic (19782014).

\section{8-2014 open water days trend significance}

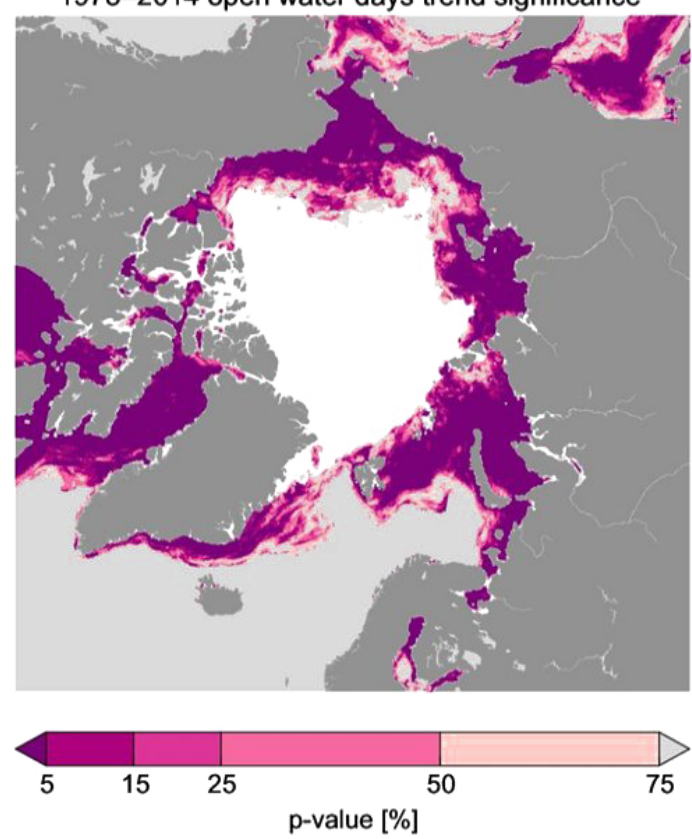

Figure 13. The probability that the trend in Fig. 12 is not significant (test of the null hypothesis). A low value $(<5 \%)$ indicates that the trend is significant.

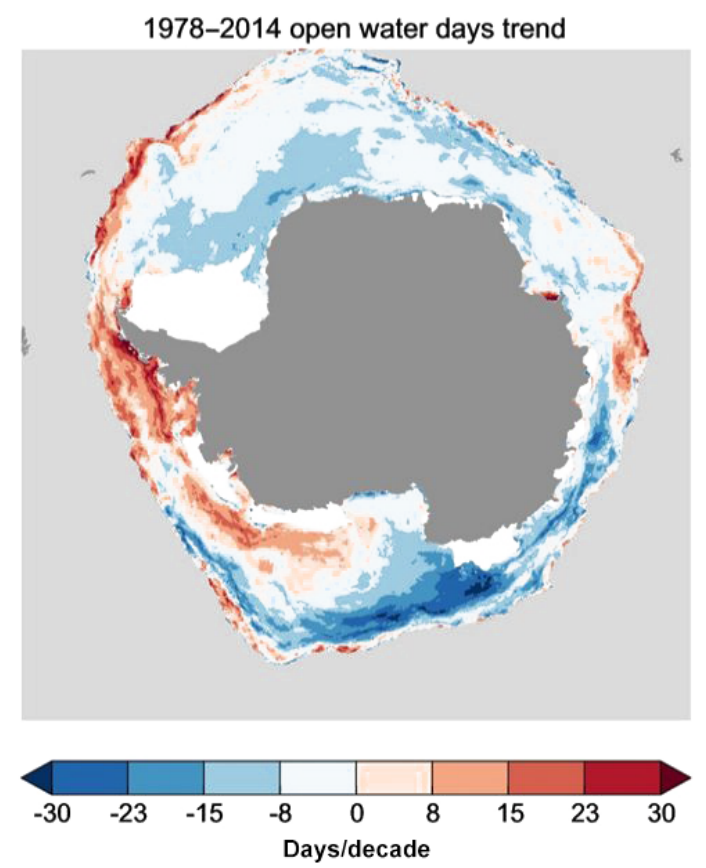

Figure 14. The linear trend in open water days in the Antarctic (1978-2014).

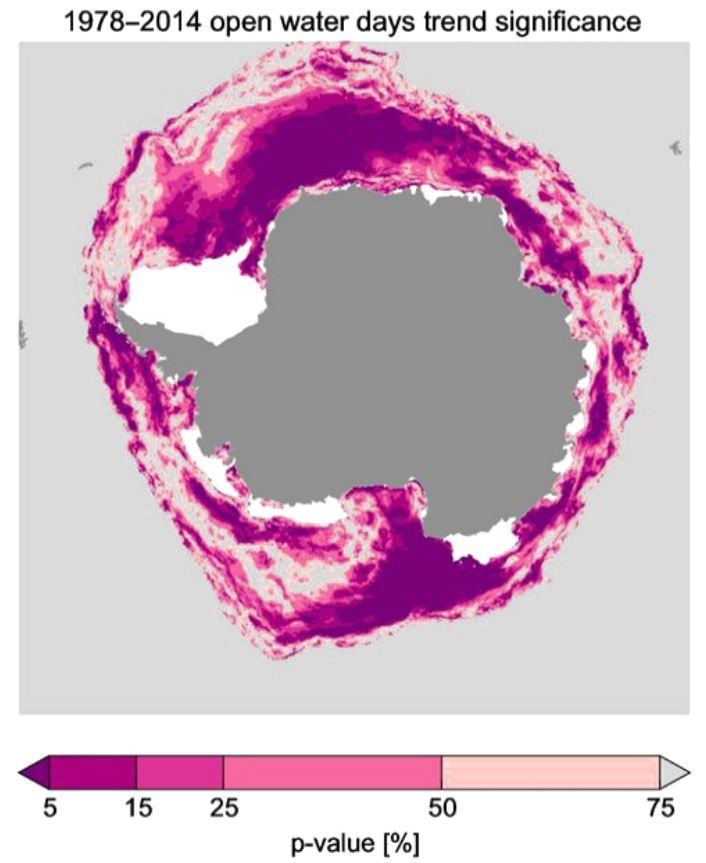

Figure 15. The probability that the trend in Fig. 14 is not significant (test of the null hypothesis). A low value $(<5 \%)$ indicates that the trend is in fact significant. 
4. Quantify the residual uncertainties. A forward model for the residual uncertainties has been developed and applied. The total uncertainty as a combination of the tiepoint variability and the representativeness uncertainty is a function of the ice concentration and it is applied on each individual measurement.

It is clear that the sea ice covers in both hemispheres have undergone large changes over the 35-year period. In the Arctic the linear trend at sea ice minimum month in September is $-94000 \mathrm{~km}^{2} \mathrm{yr}^{-1}$.

Around Antarctica there has been an increase of the total sea ice extent during all months especially downstream of the Weddell Sea and in the Ross Seas. However, there are regional differences and the ice extent has decreased along the Antarctic Peninsula in the Bellinghausen and the Amundsen Seas.

\section{Future work}

The sea ice climate record will be updated at irregular intervals. The next update is planned for autumn 2016. It will include development from the ESA sea ice climate change initiative project working towards improved sea ice climate record methodologies (Ivanova et al., 2015).

In addition, the daily near-real-time OSISAF sea ice concentration product and the ESICR are using the same algorithms and similar methodologies. One of the differences is related to the tie-point selection period, which is either the last 30 days (near-real-time) or 15 days before and after (ESICR).

In order to extend the sea ice climate record with past data the possibility of to retrieving the Nimbus 5 Electrically Scanning Microwave Radiometer (ESMR) $19 \mathrm{GHz}$ swath data from 1972 to 1977 is being investigated. These single channel data are significantly different from SMMR and SSM/I-SSMIS data and a new sea ice algorithm would have to be used.

\section{Data availability}

The sea ice concentration climate data record is available for download from Tonboe et al. (2015a, www.osi-saf.org), including documentation.

Acknowledgements. We would like to thank Irene Rubinstein, Walter Meier, and Georg Heygster for their constructive and helpful comments on the manuscript. The work was completed with support from EUMETSAT's Ocean and Sea Ice Satellite Application Facility. Stefan Kern acknowledges support given by the Center of Excellence for Climate System Analysis and Prediction (CliSAP). The SMMR data were provided by the NSIDC, the SSM/I data by Remote Sensing Systems, the numerical weather prediction model data by the ECMWF, and the SSMIS data were processed at NOAA. The ice chart data are from the US National Ice Center and NSIDC and the sea ice extent data used for comparison were provided by the NSIDC.

Edited by: C. Haas

Reviewed by: G. Heygster, W. Meier, and I. Rubinstein

\section{References}

Andersen, S.: Monthly Arctic sea ice signatures for use in passive microwave algorithms, Danish Meteorological Institute, Technical Report 98-18, 29 pp., 1998.

Andersen, S., Tonboe, R. T., and Kaleschke, L.: Satellite thermal microwave sea ice concentration algorithm comparison, in: Arctic Sea Ice Thickness: Past, Present and Future, edited by: Wadhams, P. and Amanatidis, G., Climate Change and Natural Hazards Series, 10, EUR 22416, 2006a.

Andersen, S., Tonboe, R., Kern, S., and Schyberg, H.: Improved retrieval of sea ice total concentration from spaceborne passive microwave observations using Numerical Weather Prediction model fields: An intercomparison of nine algorithms, Remote Sens. Environ., 104, 374-392, 2006b.

Andersen, S., Toudal Pedersen, L., Heygster, G., Tonboe, R., and Kaleschke, L.: Intercomparison of passive microwave sea ice concentration retrievals over the high concentration Arctic sea ice, J. Geophys. Res., 112, C08004, doi:10.1029/2006JC003543, 2007.

Belchansky, G. I. and Douglas, D. C.: Seasonal comparison of sea ice concentration estimates derived from SSM/I, OKEAN, and Radarsat data, Remote Sens. Environ., 81, 67-81, 2002.

Breivik, L.-A., Eastwood, S., Karvonen, J., Dinesen, F., Fleming, A., Hamre, T., Pedersen, L. T., Saldo, R., Buus-Hinkler, J., Hackett, B., Ardhuin, F., and Jensen, M. B.: Quality information document for OSI TAC sea ice products, MyOcean ref. MYOF-OSIQUID-SEAICE, 1.10, 62 pp., 9 March 2015.

Cavalieri, D. J. and Parkinson, C. L.: Arctic sea ice variability and trends, 1979-2010, The Cryosphere, 6, 881-889, doi:10.5194/tc6-881-2012, 2012

Cavalieri, D. J., Gloersen, P., and Campbell, W. J.: Determination of Sea Ice Parameters with the NIMBUS-7 SMMR, J. Geophys. Res., 89, 5355-5369, 1984.

Cavalieri, D. J., Parkinson, C. L., Gloersen, P., Comiso, J. C., and Zwally, H. J.: Deriving long-term time series of sea ice cover from satellite passive-microwave multi-sensor data sets, J. Geophys. Res., 104, 15803-15814, 1999.

Close, S., Houssals, M.-N., and Herbaut, C.: Regional dependence in the timing of onset of rapid decline in Arctic sea ice concentration, J. Geophys. Res.-Oceans, 120, 8077-8098, doi:10.1002/2015JC011187, 2015.

Comiso, J. C.: Characteristics of arctic winter sea ice from satellite multispectral microwave observations, J. Geophys. Res., 91, 975-994, 1986.

Comiso, J. C, Cavalieri, D. J., Parkinson, C. L., and Gloersen, P. Passive microwave algorithms for sea ice concentration: A comparison of two techniques, Remote Sens. Environ., 60, 357-384, 1997.

Comiso, J. C., Kwok, R., Martin, S., and Gordon, A. L.: Variability and trends in sea ice extent and ice production in the Ross Sea, 
J. Geophys. Res., 116, C04021, doi:10.1029/2010JC006391, 2011.

Dedrick, K. R., Partington, K., Van Woert, M., Bertoia, C. A., and Benner, D.: U.S. National/Naval Ice Center Digital Sea Ice Data and Climatology, Can. J. Remote Sens., 27, 457-475, 2001.

Drusch, M., Wood, E. F., and Lindau, R.: The impact of the SSM/I antenna gain function on land surface parameter retrieval, Geophys. Res. Lett., 26, 3481-3484, 1999.

Eastwood, S., Jensen, M. B., Lavergne, T., Sørensen, A. M., and Tonboe, R.: Global Sea Ice Concentration Reprocessing. Product User Manual, EUMETSAT OSISAF, Document version: 2.2, Data set version: 1.2, August 2015.

Emery, W. J., Fowler, C., and Maslanik, J.: Arctic sea ice concentrations from special sensor microwave imager and advanced very high resolution radiometer satellite data, J. Geophys. Res., 99, 18329-18342, 1994.

Fetterer, F.: A Selection of Documentation Related To National Ice Center Sea Ice Charts in Digital Format, National Snow and Ice Data Center (NSIDC), Boulder, Colorado, USA, NSIDC Special Report \# 13, 2006.

Fetterer, F. and Fowler, C.: National Ice Center Arctic sea ice charts and climatology, NSIDC, Boulder, Colorado, USA, 2006, updated 2009.

Fetterer, F., Knowles, K., Meier, W., and Savoie, M.: Sea Ice Index, version 2. 1978-2015, NSIDC, Boulder, Colorado, USA, doi:10.7265/N5736NV7, 10 August 2016.

Gloersen, P. and Barath, F. T.: A scanning multichannel microwave radiometer for Nimbus-G and SeaSat-A, IEEE J. Oceanic Eng., 2, 172-178, 1977.

Gloersen, P., Campbell, W. J., Cavalieri, D. J., Comiso, J. C., Parkinson, C. L., and Zwally, H. J.: Arctic and Antarctic sea ice, 19781987: satellite passive-microwave observations and analysis, National Aeronautics and Space Administration, Washington, DC, NASA SP-511, 319 pp., 1992.

Goosse, H. and Zunz, V.: Decadal trends in the Antarctic sea ice extent ultimately controlled by ice-ocean feedback, The Cryosphere, 8, 453-470, doi:10.5194/tc-8-453-2014, 2014.

Holland, P. R. and Kwok, R.: Wind-driven trends in Antarctic sea ice drift, Nat. Geosci., 5, 872-875, 2012.

Hollinger, J. P., Peirce, J. L., and Poe, G. A.: SSM/I instrument evaluation, IEEE T. Geosci. Remote, 28, 781-790, 1990.

Ivanova, N., Pedersen, L. T., Tonboe, R. T., Kern, S., Heygster, G., Lavergne, T., Sørensen, A., Saldo, R., Dybkjær, G., Brucker, L., and Shokr, M.: Inter-comparison and evaluation of sea ice algorithms: towards further identification of challenges and optimal approach using passive microwave observations, The Cryosphere, 9, 1797-1817, doi:10.5194/tc-9-17972015, 2015.

Kållberg, P., Simmons, A., Uppala, S., and Fuentes, M.: The ERA40 archive, ERA-40 Project Report Series, ECMWF, Reading, 2004.

Kern, S., Bunzel, F., Debernand, J., Heiberg, H., Killie, M. A., Koldunov, N., and Lavergne, T.: ESA Sea Ice Climate Change Initiative: Phase 1, D4.2 Climate Assessment Report, Document Ref.: SICCI-CAR, Version 1, 26 November 2014.

Meier, W.: Scanning Multichannel Microwave radiometer (SMMR) reprocessing for EUMETSAT, OSI SAF Visiting Scientist Report, 9 pp., 2008.
Parkinson, C. L.: Spatially mapped reductions in the length of the Arctic sea ice season, Geophys. Res. Lett., 41, 4316-4322, 2014

Parkinson, C. L. and Cavalieri, D. J.: Arctic sea ice variability and trends, 1979-2006, J. Geophys. Res., 113, C07003, doi:10.1029/2007JC004558, 2008.

Poe, G., Uliana, E. A., Gardiner, B. A., vonRentzell, T. E., and Kunkee, D. B.: Geolocation error analysis of the Special Sensor Microwave Imager/Sounder, IEEE T. Geosci. Remote, 46, 913-922, 2008.

Rayner, N. A., D. E., Parker, Horton, E. B., Folland, C. K. Alexander, L. V., Rowell, D. P., Kent, E. C., and Kaplan, A.: Global analysis of sea surface temperature, sea ice, and night marine air temperature since the late nineteenth century, J. Geophys. Res., 108, 4407, doi:10.1029/2002JD002670, 2003.

Rogers, J. C. and Hung, M.-P.: The Odden ice feature of the Greenland Sea and its association with atmospheric pressure, wind, and surface flux variability from reanalyses, Geophys. Res. Lett., 35, L08504, doi:10.1029/2007GL032938, 2008.

Smith, D. M.: Extraction of winter sea ice concentration in the Greenland and Barents Seas from SSM/I data, Int. J. Remote Sens., 17, 2625-2646, 1996.

Steffen, K. and Schweiger, A.: NASA team algorithm for sea ice concentration retrieval from Defense Meteorological Satellite Program special sensor microwave imager: Comparison with Landsat satellite imagery, J. Geophys. Res., 96, 21971-21988, 1991.

Tonboe, R. and Toudal, L.: Classification of new-ice in the Greenland Sea using Satellite SSM/I radiometer and SeaWinds scatterometer data and comparison with ice model, Remote Sens. Environ., 97, 277-287, 2005.

Tonboe, R. T., Eastwood, S., Lavergne, T., Sørensen, A. M., Rathmann, N., Dybkjær, G., Pedersen, L. T., Høyer, J. L., and Kern, S.: OSI SAF global sea ice concentration data record - OSI-409a, doi:10.15770/EUM_SAF_OSI_0005, 2015a.

Tonboe, R., Pfeiffer, R.-H., Jensen, M. B., Howe, E., and Eastwood, S.: Validation report for Global sea ice concentration reprocessing, EUMETSAT OSISAF Products OSI-409, Osi-409a, OSI430, Document version: 2.0, 30 pp., April 2015b.

Wentz, F. J.: A model function for ocean microwave brightness temperatures, J. Geophys. Res., 88, 1892-1908, 1983.

Wentz, F. J.: User's Manual, SSM/I Antenna Temperature Tapes, Revision 1, Remote Sensing Systems, Santa Rosa, California, USA, RSS Technical Report 120191, 1991.

Wentz, F. J.: User's Manual, SSM/I Antenna Temperature Tapes, Revision 2, Remote Sensing Systems, Santa Rosa, RSS Technical Report 120193, 1993.

Wentz, F. J.: A well-calibrated ocean algorithm for SSM/I, J. Geophys. Res., 102, 8703-8718, 1997.

Wentz, F. J.: User's Manual, SSM/I Antenna Temperature, Version 6, Remote Sensing Systems, Santa Rosa, RSS Technical Memo 082806, 2006.

Wentz, F. J., Ricciardulli, L., Hilburn, K., and Mears, C.: How much more rain will global warming bring?, Science, 317, 233-235, doi:10.1126/science.1140746, 2007.

Zhang, X. D. and Walsh, J. E.: Toward a seasonally ice-covered Arctic Ocean: Scenarios from the IPCC AR4 model simulations, J. Climate, 19, 1730-1747, 2006. 